\title{
Limitations of the Perioperative Cardiovascular Evaluation for Assessing Coronary Artery Disease: A Case Report
}

\author{
Rady Ho, MD \\ Thomas Jefferson University Hospital, rady.ho@jefferson.edu \\ Mitul Kanzaria, MD \\ Thomas Jefferson University, Mitul.Kanzaria@jefferson.edu \\ Paul Walinsky, MD \\ Thomas Jefferson University Hospital, Paul.Walinsky@jefferson.edu
}

Follow this and additional works at: https://jdc.jefferson.edu/tmf

Part of the Cardiology Commons, and the Internal Medicine Commons

Let us know how access to this document benefits you

\section{Recommended Citation}

Ho, MD, Rady; Kanzaria, MD, Mitul; and Walinsky, MD, Paul (2016) "Limitations of the Perioperative Cardiovascular Evaluation for Assessing Coronary Artery Disease: A Case Report," The Medicine Forum: Vol. 17 , Article 7.

DOI: https://doi.org/10.29046/TMF.017.1.008

Available at: https://jdc.jefferson.edu/tmf/vol17/iss1/7

This Article is brought to you for free and open access by the Jefferson Digital Commons. The Jefferson Digital Commons is a service of Thomas Jefferson University's Center for Teaching and Learning (CTL). The Commons is a showcase for Jefferson books and journals, peer-reviewed scholarly publications, unique historical collections from the University archives, and teaching tools. The Jefferson Digital Commons allows researchers and interested readers anywhere in the world to learn about and keep up to date with Jefferson scholarship. This article has been accepted for inclusion in The Medicine Forum by an authorized administrator of the Jefferson Digital Commons. For more information, please contact: JeffersonDigitalCommons@jefferson.edu. 


\title{
Limitations of the Perioperative Cardiovascular Evaluation for Assessing Coronary Artery Disease: A Case Report
}

\author{
Rady Ho, MD, Mitul Kanzaria, MD, and Paul Walinsky, MD
}

\begin{abstract}
INTRODUCTION
The American College of Cardiology (ACC) and the American Heart Association (AHA) published pre-operative risk stratification guidelines in 2014 These guidelines have routinely been used by physicians to pre-operatively risk stratify patients. In this case report, a patient was found to have multi-vessel coronary artery disease post-operatively in the setting of unremarkable cardiac work-up preoperatively. This case highlights a limitation of the 2014 ACC/AHA guidelines.
\end{abstract}

\section{CASE PRESENTATION}

A 59 year-old female with a past medical history significant for peripheral vascular disease (PVD) with angioplasty of the left common iliac artery, carotid stenosis treated with angioplasty, type II diabetes, hypertension, and hyperlipidemia who was seen for preoperative evaluation in anticipation of femoropopliteal bypass

Preoperatively, her risk for a major adverse cardiac and cerebrovascular event (MACE) was approximately $1 \%$ via the NSQIP calculator and 1.51\% via the Gupta calculator. Due to the patient's elevated risk and limited functional capacity (METS <4), further work-up with an exercise nuclear stress test was recommended. ${ }^{1}$ The exercise nuclear stress test revealed a Duke Treadmill Score of negative 5 and 0.5-1 $\mathrm{mm}$ horizontal ST depressions in leads $\mathrm{V} 5-6$, but myocardial perfusion imaging (MPI) showed no identifiable perfusion defect or evidence of transient ischemic dilation (TID). Given the non-specific ST depressions and normal MPI without evidence of TID, her risk of significant coronary artery disease was assessed to be low and she proceeded to surgery.

\section{OUTCOME AND FOLLOW-UP}

On post-op day 1 she complained of nausea and chest pressure, and an EKG revealed 3-4 mm downsloping ST depressions in leads V3-V6, I and II with $3 \mathrm{~mm}$ ST elevation in lead aVR. Her initial troponin was negative. A stat echocardiogram showed an ejection fraction (EF) of $40 \%$ and hypokinesis of the inferoseptal, inferior, and inferolateral walls. Urgent cardiac catheterization revealed an $80 \%$ eccentric stenosis in the distal left main artery, diffuse $40 \%$ stenosis in the mid circumflex, and 100\% stenosis in the proximal right coronary artery. The patient underwent emergent coronary artery bypass grafting (CABG) with the left internal mammary artery to the left anterior descending artery, and saphenous vein grafts to the first and second marginal arteries. The patient eventually recovered and was discharged to a rehabilitation facility.

\section{DISCUSSION}

Peripheral vascular disease affects about 5 million Americans. One of the treatment modalities is surgical revascularization, such as femoropopliteal bypass. Though the cardiovascular risk associated with vascular surgery is about $1 \%$, cardiac complications are the leading cause of morbidity and mortality. ${ }^{3}$ The incidence of perioperative myocardial infarction in surgeries involving vascular procedure ranges from $3 \%$ to $17 \%{ }^{4}$ Consequently, the American College of Cardiology (ACC) and the American Heart Association (AHA) developed the 2014 ACC/AHA Perioperative Guideline for preoperative risk stratification for cardiac events. This case highlights the limitations of the current guidelines for coronary artery disease (CAD).

In this case, because of her elevated risk for MACE and limited functional capacity, a stress test was done and showed ST depressions in leads V5-V6. It has been shown that ST depressions > $1 \mathrm{~mm}$ in leads V4-V6 has a $94.7 \%$ specificity and $11.2 \%$ sensitivity for CAD. ${ }^{5}$ Given the high specificity of the ST depression for ischemia, MPI was performed. With MPI, we look for a perfusion defect or evidence of TID. Numerous studies have shown the relationship between TID and CAD. A study by Mazzanti et al showed that TID with an abnormal MPI is a marker of severe CAD with $77 \%$ sensitivity and $92 \%$ specificity. ${ }^{6}$ TID also confers increased risk of cardiac events. However, with normal MPI, TID does not predict severity of CAD, and thus does not warrant invasive coronary angiography. ${ }^{8}$ With normal MPI and absence of TID, it was reasonable to conclude that this patient was at low risk for CAD and no further intervention was warranted.

Unfortunately, the patient had an acute coronary syndrome post-operatively and was found to have significant multivessel coronary artery disease, despite appropriate risk stratification for CAD using the current perioperative guideline. Since her CAD involved both RCA and left main artery, her normal MPI is likely secondary to balanced myocardial malperfusion. MPI requires about $15-20 \%$ difference among different myocardial regions to detect ischemia. Therefore, if there is diffuse myocardial hypoperfusion, there will be insufficient difference for detection of ischemia resulting in false negative MPI. ${ }^{9}$ The occurrence of false negative 
The Medicine Forum, Vol. 17 [2016], Art. 7

MPI associated with balanced ischemia is unknown. In conclusion, this case demonstrates the limitations of the current perioperative guideline to diagnose severe CAD in the preoperative evaluation.

\section{KEY POINTS}

- ACC/AHA perioperative guideline is a useful risk stratification tool to predict cardiac complications in patients undergoing surgical procedures.

- This case highlights the limitations of stress testing as part of the perioperative evaluation, especially in patients with multivessel CAD.

- To date, the occurrence of false negative stress tests due to balanced ischemia during pre-operative evaluation is unknown.

- A negative stress test does not rule out left main/triple vessel disease and does not predict risk of ACS.

\section{REFERENCES}

1. Fleisher, Lee A., Kirsten E. Fleischman, Susan A. Barnason, Joshua A. Beckman, Biykem Bozkurt, Victor G. Davila-Roman, Marie D. GerhardHerman, Thomas A. Holly, Andrew D. Auerbach, Garvan C. Kane, Joseph E. Marine, M. T. Nelson, Crystal C. Spencer, Annemarie Thompson, Henry H. Ting, and Barry F. Uretsky. "2014 ACC/AHA Guideline on Perioperative Cardiovascular Evaluation and Management of Patients Undergoing Noncardiac Surgery: Executive Summary." Journal of the American College of Cardiology (2014): 735-1097.

2. Kasapis, Christos, and Hitinder S. Gurm. "Current Approach to the Diagnosis and Treatment of Femoral-Popliteal Arterial Disease. A Systematic Review." Current Cardiology Reviews 5.4 (2009): 296-311.
3. Shah, Tejas R., Frank J. Veith, and Stephen M. Bauer. "Cardiac Evaluation and Management before Vascular Surgery." Curr Opin Cardiol 29 (2014): 499-505.

4. Gupta, Prateek K., Himani Gupta, Abhishek Sundaram, Manu Kaushik, Xiang Fang, Weldon J. Miller, Dennis J. Esterbrooks, Claire B. Lynch, Iraklis I. Pipinos, Jason M. Johanning, Thomas G. Lynch, R. A. Forse, Syed M. Mohiuddin, and Aryan N. Mooss. "Development and Validation of a Risk Calculator for Prediction of Cardiac Risk After Surgery." Cardiovascular Surgery 124 (2011): 381-87.

5. Maganis, Jonathan C., David A. Drimmer, Ferdinand B. Rojo, Sherief H. Gamie, Ronald Startt H. Selvester, and Myrvin H. Ellestad. "Enhanced Recognition of Ischemia by Three Variable Analysis of the Exercise Stress Test." Journal of Electrocardiology 46.6 (2013): 644-48

6. Mazzanti, Marco, Guido Germano, Hosen Kiat, Paul B. Kavanagh, Erick Alexanderson, John D. Friedman, Rory Hachamovitch, Kenneth F. VanTrain, and Daniel S. Berman. "Identification of Severe and Extensive Coronary Artery Disease by Automatic Measurement of Transient Ischemic Dilation of the Left Ventricle in Dual-Isotope Myocardial Perfusion SPECT." Journal of the American College of Cardiology 27.7 (1996): 1612-620.

7. Mcclellan, Joseph R., Mark I. Travin, Steven D. Herman, John I. Baron, Robert J. Golub, James J. Gallagher, David Waters, and Gary V. Heller. "Prognostic Importance of Scintigraphic Left Ventricular Cavity Dilation During Intravenous Dipyridamole Technetium-99m Sestamibi Myocardial Tomographic Imaging in Predicting Coronary Events." The American Journal of Cardiology 79.5 (1997): 600-05

8. Valdiviezo, Carolina, Apurva A. Motivala, Rory Hachamovitch, Murthy Chamarthy, Pablo C. Navarro, Robert J. Ostfeld, Mimi Kim, and Mark I. Travin. "The Significance of Transient Ischemic Dilation in the Setting of Otherwise Normal SPECT Radionuclide Myocardial Perfusion Images." Journal of Nuclear Cardiology 18.2 (2011): 220-29.

9. Aarnoudse, Wilbert H., Kees-Joost Bm Botman, and Nico Hj Pijls. "False-negative Myocardial Scintigraphy in Balanced Three-vessel Disease, Revealed by Coronary Pressure Measurement." Acute Cardiac Care 5.2 (2003): 67-71.

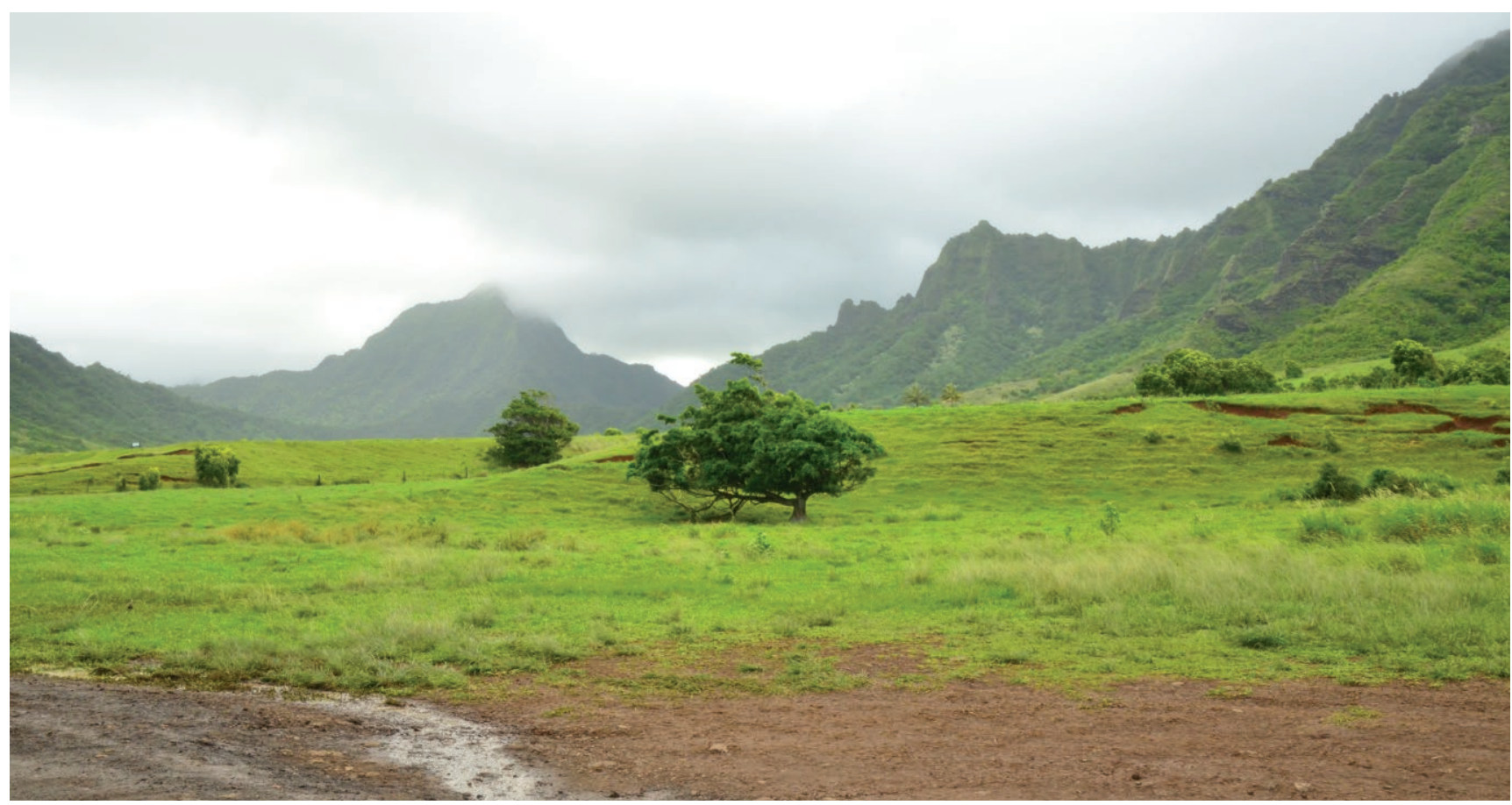

Anusha G. Govind, MD 